\title{
The institutional environment of extractive industries as a driver of sustainable development in resource-driven economies
}

\author{
Valentin Knysh ${ }^{1}$, and Tatiana Ponomarenko ${ }^{2}$ \\ ${ }^{1}$ Institute of Economic Problems n.a. G.P. Luzin is a separate subdivision of the Federal Research \\ Center, Kola Scientific Center of the Russian Academy of Sciences \\ ${ }^{2}$ Saint-Petersburg Mining University (SPMU)
}

\begin{abstract}
Many resource-driven economies (RDE) of low- and middleincome countries are in captivity of the "resource curse", which is usually associated with the presence in the country of natural reserves of metals, minerals, oil, gas. For several decades, macroeconomic and institutional theories have differently explained why resource dependence in most countries leads to weak economic growth and poverty. Numerous hypotheses and econometric studies expand knowledge about the phenomenon of the resource curse, but the problem for many countries with RDE remains unresolved. In the last 7-8 years prevails the opinion that mining can help countries with RDE to enter the trajectory of sustainable growth. But for this it is necessary to improve the quality of national institutions. It remains unclear how to stimulate a positive transformation of the institutional environment of a resource-dependent economy. The idea of the work is to focus on changing the institutional environment of the extractive industries, and not on the country's economy as a whole. This approach has been little studied, but its application in the context of the Sustainable Development Goals (SDGs, 2015-2030) can help increase the contribution of the extractives sector to the sustainable development of a country with RDE and low or middle income. Institutionalization of international sectoral initiatives, introduction of international standards and best practices into the institutional environment of the national extractives sector will have a stimulating effect. For responsible investors, the environmental dimension of sustainability is becoming increasingly important.
\end{abstract}

\section{Introduction}

\subsection{Resource dependence and resource wealth}

The resource dependence of a country is usually assessed by the share of natural resources in GDP or total merchandise exports. Resource wealth is usually understood as the reserves of mineral resources (metals, minerals, oil, natural gas) located in the depths. The mined 
mineral resources generate cash flows from the export of raw materials, creating the financial basis for the RDE.

A situation in a resource-dependent country with a poorly diversified economy when the rates of economic growth remain below the world average is called the "resource curse". A low average per capita income is its accompanying sign. As the examples of Australia, Canada, Norway and other countries show, the resource curse can be avoided if the revenues from resource exports are invested in the diversification of the economy.

The economy of resource-dependent countries with low and middle incomes, in a certain sense, becomes a hostage to any circumstances that negatively affect the commodity market and lead to a slowdown in the economic growth. What really matters is that the potential for productivity growth in the extractive industries is limited and that profitable reserves of mineral resources are depleting.

The study of ICMM and UNCTAD (2012) data revealed [1] that out of 214 world countries, 82 are resource dependent (the share of resources exceeds $30 \%$ in the country's merchandise exports). Of these, 58 countries have low or middle income and 24 - high income. At the same time, mining economies are less efficient than oil and gas ones. Only 5 mining countries out of 37 (i.e. 14\%) have high incomes, and the remaining 32 countries have low or middle incomes, while among the 48 oil and gas dependent countries, 19 countries have high incomes (or 40\%), and low or medium level - 29 countries with RDE. Three countries (Republic of Korea, Mozambique and Sudan) in the UN classifications belong to the mining and oil and gas countries at the same time.

\subsection{Resource Wealth for Sustainable Development: An Institutional Approach}

To date, there is no consensus on the causality of commodity dependence and the ways to overcome it. A shaky consensus is that resource wealth can be both a driver and an obstacle to development, and the completeness and quality of institutions play a key role in it.

Conducted since the mid-1990s. extensive empirical research has given various, sometimes opposite, explanations for the phenomenon of slower growth in the presence of resource wealth. Proponents of the institutionalist approach came to the conclusion that even at the heart of the versions about the "Dutch disease" and the volatility of commodity prices, there is a problem of the quality of certain institutions [2]. Later it was shown that the abundance of resources in itself has a positive effect on growth, while the dependence on resources does not have an effect on growth [3]. The transition to the use of proxy variables for the analysis of factor dependences made it possible to explain the emerging negative effects not by an excess of natural resources, but by the weakness of institutions and poor management of macroeconomic risks. This gave rise to speaking not about the resource curse, but about the "institutional curse" [4].

Within the proponents of the institutionalist approach, two diverging views appeared to the cause of the poor quality of institutions in low- and middle-income countries with RDE. Some suggest that an abundance of resources inevitably leads to the degradation of institutions, as a result of which growth and development slow down. Others argue that poor quality institutions may not be directly related to resource wealth. For example, one of the studies conducted on a sample of 68 mining and 39 oil and gas RDE s revealed a tendency: a better institutional environment of the national economy ensures higher socioeconomic development in countries with RDE [5].

Many authors call the "pursuit" for natural rent the main barrier to the growth and development of countries with RDE, and some call the volatility of natural rent [6]. The desire to appropriate resource rent can be a driving force behind the "opportunistic" 
behavior of power elites and an obstacle in attempts to reform institutions in order to improve the efficiency of mineral resource management.

New opportunities for better use of resource wealth are emerging in low- and middleincome countries with RDE as part of the implementation of the SDG 17 concept (20152030). The paper proposes to focus on the institutional environment of the extractive industry, and not on the country's economy as a whole. The transition from the national to the sectoral level of analysis allows us to consider the institutional structure of the national mining sector from a different angle, including as a part of the global sector of primary resources.

The work is aimed at describing a model of the institutional environment of the extractive industry and assess the impact of international sectoral initiatives on the transition of countries with RDE and low or middle income to sustainable development. The ecological component of the sustainability of the subsoil resource extraction sector is considered separately.

\section{Materials and methods}

The sources of the initial data were scientific articles on the research topic indexed in international databases, as well as monographs, research reports, documents of the UN and other organizations related to the formation and implementation of the Sustainable Development Goals until 2030.

The research was carried out in the following logical sequence. At the first stage, publications were studied that reflect the key points in the evolution of scientific views on the problem of the "resource curse". Then, works were identified on the conceptualization of the institutional environment of the resource extraction sector, and its framework structure was described using the O. Williamson's typology of institutions. Next, the relationship between the institutional environment of the mining sector and the SDGs was discussed. Finally, the ecological factor of sustainable development in relation to the extraction of resources is considered.

The authors make the following stipulations. The terms "resources", "mineral resources", "subsoil resources" are used synonymously and include metal ore, other solid minerals, oil and natural gas. The resources can be found in the subsoil in the form of reserves or take a commodity form in the markets of mineral raw materials. The concepts of "extractive industry" and "subsoil use" are considered both in the technological aspect (exploration of the subsoil, mining, enrichment, waste management) and in the economic aspect (assessment of the effectiveness of the extraction and use of resources). The nationality of the industrial assets of the extractive sector for the purposes of the study is not of fundamental importance.

\section{Results and discussion}

\subsection{Conceptualizing the institutional environment of the extractive industry}

Since there is no generally accepted definition of the institutions, let us clarify the features of this concept. We view institutions as human-created restrictions, that shape the interactions, and with them the incentives (political, social, or economic) [7]. Along with restrictions (formal or informal rules) and incentives, institutions have mechanisms of coercion (sanctions for deviations from the rules) that structure repetitive situations of interaction. Let's distinguish four types of interaction rules: conventions, ethical rules, 
customs, formal private rules and state laws [8] Each type of rules is associated with a certain type of coercion and characterizes a certain type of institution. Conventions do not imply coercion, they relate to coordinating institutions without conflicts, when an actor's deviation from the rules entails inconsistency of actions and subsequent punishment in the form of a reduction in gain [8].

Under the paradigm of sustainable development, the national mining sector can be considered in two aspects: from the point of view of the sector's contribution to the sustainable development of a country with RDE and from the point of view of sustainable development of the sector itself. These two aspects are interrelated. The transparency of the mineral resource management system and the reduction of the "asymmetry of power" between the government, the extractive industry and other stakeholders are considered to be important prerequisites for increasing the stability of the mining sector in the face of growing uncertainty and risks [9].

Sector regulation is believed to reduce risks and uncertainty aimed at creating accountable institutions which build trust and enable agreement on a common value for all stakeholders.

There is a consensus that "institutions" are of vital importance, but an understanding of their relationship with general and specific mechanisms of regulation of the extractive industries is required A study carried out under the UNU-WIDER program presents the concept and typology of institutions by O. Williamson, adapted to mining sector [10].

O. Williamson's typology forms four levels ("layers") of institutions [11]:

(1) social affiliation (customs, traditions, beliefs, religion) - the upper level;

(2) institutional environment (formal rules of the game for the implementation of economic transactions);

(3) governance (obligations of the parties involved in transactions, or "playing the game");

(4) resource allocation (market analysis and decision making in project implementation) - lower level.

In the neoinstitutional interpretation, the concept of "institutional environment" includes only formal institutions of the level (2) and contracts of the level (3). From the point of view of combating the resource "curse" and the use of subsoil resources for sustainable development, level (2) is the most significant, since it is the "area" of the state's competence, which establishes the rules for subsoil use and the functioning of the extractive industry.

The institutional environment of the extractive industries (IE EI) sets at the level (2) the degree of completeness and the qualities of the system of state regulation of subsoil use relations in countries with RDE. The framework of the IE EI includes:

- constitutional provisions and codes that establish the legal status of subsoil and subsoil resources as part of natural resources, defining the subjects of ownership, the forms use of subsoil, the ways of involving resources into circulation;

- legislative and regulatory acts that determine the sectoral structure of the mining sector, the procedure for granting licenses for the right to use the subsoil, policies and strategies for subsoil use, environmental protection and the rights of local communities, issues of taxation, distribution of income and control.

- $\quad$ sectoral (industry-specific) legal regimes governing obligations arising from rights to primary resources, including employment and procurement in local markets; as well as regimes that form the legal basis for contracts and agreements that underlie investment, sales and export decisions in the process of implementation of mining projects; 
- $\quad$ various special tax and other regimes introduced as part of the "good governance" of the sector, for example, in the case of the establishment of stabilization and savings funds, or sovereign wealth funds, or the adoption of legislation on transparency.

The establishment of institutions is not equivalent to the emergence of economic results. There is no clear understanding of how institutions can be forced to change in a manner that they could contribute to sustainable development based on subsoil use in the interests of all stakeholders, overcoming the opportunism of the power elites.

O. Williamson identified the so-called "gaps in knowledge", which violate the institutional environment integrity and subsequently lead to "governance gaps". If the "gaps in knowledge" are presented as independent variables, they become controllable factors in the IE EI development, which are responsible for changes. The quality of the IE EI determines the efficiency of management of economic systems and processes and directly affects the results of economic activity. If the results are consistently unsatisfactory, for example, there is no progress in economic growth, then the IE EI should be amended.

\subsection{The institutional environment of the extractive industries in the context of the Sustainable development goals: a global regulatory dimension}

Extractive industries in RDE countries are part of the global minerals sector, which is characterized by complex transnational value chains and is subject to risk and uncertainty. The sources of threats can be both economic in nature (for example, the price volatility) and non-economic in nature (for example, the covid 19 pandemic).

As the forms and value chains become more complex, the need for more flexible and reliable institutional mechanisms to support sustainable development at the micro, meso and macro levels increases. Their emergence and replication is facilitated by "soft" supranational regulation designed to increase the adaptability of extractive industries in countries with RDE to conditions of uncertainty.

International initiatives fulfill the function of "global governance". The "governance" concept means "all management processes by the government of the state, market or network over the social system (including formal or informal organization, territory) with the help of laws, norms, power or the language of an organized society" [12]. The "global governance" can be interpreted as a directed development of integration through institutional changes in any area [13].

Countries with RDE may have an ambiguous attitude towards supranational institutions for fear that they would become a means of competitive pressure. However, the "soft" international regulation based on the principles of voluntariness and non-discrimination, performing the functions of information, coordination, training and assessment, acts as a mechanism to eliminate "gaps in knowledge" according to O. Williamson in relation to national institutions of subsoil use. The legitimacy of such regulation is ensured by conventional norms and agreements.

The 2030 Agenda for Sustainable Development, which sets target development priorities for 193 countries in order to build a more sustainable world and neutralize likely global threats, has signs of a mega-regulator in relation to the global primary resources sector. The SDG matrix includes 17 goals, 169 targets and 231 indicators that have stimulating impacts on the global extractives sector in three dimensions: economic, social and environmental. These impacts are broadcast to international and national institutions and are designed to stimulate positive changes in the institutional environment of the extractive industries in countries with RDE. The International resource group of the United Nations Environment Program, which conducted fundamental research on the management 
of mineral resources (2017-2019), concluded that the 2030 Agenda for Sustainable Development has given a new impetus to the usage of the wealth of subsoil resources to improve living conditions in countries with $\operatorname{RDE}[14,19]$. A correlation was found between mining and the SDGs, which confirmed that, with good governance the mining sector offers tremendous opportunities for sustainable development, especially in low-income countries [9].

The problem is that low- to middle-income RDE countries, unlike high-income RDE countries, may not be sufficiently susceptible to the immediate impact of the SDGs. The correction of national institutions may not occur or may be insufficient. This gap is intended to be eliminated by international structures and initiatives that share the values of sustainable and inclusive development, such as ICMM, NRGI, EITI, IRMA, MGI, IFC. They develop standards of conduct and reporting for extractive industries and companies, as well as tools to measure progress and competitiveness. Indexes are used to measure competitive positions, the most famous of which are MCI, RCI, RGI.

At the basic level, the competitiveness of extractive industries is determined by two main factors, the quality of the mineral resource base and the quality of the institutional environment of the extractive industries. Institutionalization and integration of international sectoral initiatives should be seen by low- to middle-income countries with RDE as an essential condition and an opportunity to improve the competitiveness of the national extractives sector in order to meet the goals of sustainable development.

\subsection{Environmental aspects of the sustainability of the extractives sector}

While the extractive industries can make a significant contribution to economic growth and development, extractive industries leaves a significant "carbon footprint" and has a negative impact on the environment. The importance of the environmental dimension in the structure of sustainable development is characterized by its reflection in the SDGs. The environmental dimension is present in 13 out of 17 SDGs, and in six SDGs $(6,7,12,13,14$ and 15$)$, the share of ecology is more than $40 \%$. Environmental factors associated with the extraction of subsoil resources are present in four SDGs $(12,13,14,15)$. If we restrict ourselves to the extraction of resources on land, then the tasks and indicators, mainly related to ecology, are presented in three SDGs: 12 - responsible consumption and production, 13 - combating climate change, 15 - preservation of terrestrial ecosystems.

The main environmental problems in the extraction of subsoil resources are associated with emissions of harmful substances into the air and water bodies, the accumulation of toxic waste, erosion and soil pollution, disturbance of natural landscapes, and degradation of ecosystems. There are also threats of breakage of tailings dams.

A challenge for the extractives sector is the threat of climate change. The sector is forced to adapt exploration and production to changing patterns of demand for energy and minerals [15]. Stationary energy and transport sources in mines are associated with $\mathrm{CO}_{2}$ emissions, and extractive companies must address the decarbonisation problem. The main path to reducing emissions is the introduction of low-carbon technologies and the transition to renewable energy sources, as defined in the SDGs. But the creation of a new energy infrastructure will require significantly more certain metals and minerals than the traditional one [16]. In this regard, countries with RDE that have such resources open up additional opportunities to expand their activities and meet growing demand.

Investments are needed for the business expansion. The environmental factor plays an increasingly important role in financial markets, changing the conditions for its participants. Thus, for example, in 2020 The European Union has approved a Sustainable Investment Regulation (EU Taxonomy) [17], which restricts EU access to international financial 
capital for projects that do not meet environmental sustainability criteria. An economic activity is considered environmentally sustainable if it benefits the environment more than it does harm. The new rules for environmental goals such as climate change mitigation and climate change adaptation will come into effect in 2022.

There is a problem of inconsistency of some SDGs related to the solution of environmental objectives in the extractives sector. For example, it is necessary to reduce mining waste and at the same time reduce greenhouse gas emissions against the background of deteriorating quality of mineral resources. Low- and middle-income countries with RDE need access to international advice to find sustainable solutions to environmental challenges and develop strategies for environmental sustainability [15].

The environmental regulation should become an integral part of "good governance" in the extractive industries of countries with RDE. Proper management of the environmental impacts of mining operations must cover the entire life cycle of a field development project, from the decision making to the completion of the project. The world's best practices indicate that an institutional balancing of the management of the environmental and social impacts of the sector on the environment and local communities will be required on the principle of the equivalence of these two dimensions [18].

Thus, in order to improve the environmental sustainability of the extractives sector in countries with RDE, changes in the institutional environment are required in two directions. The first is related to the institutionalization of international environmental initiatives and the implementation of best practices. The second is related with filling the institutional environment of the extractives sector with the basic institutions of environmental protection and eliminating the contradictions between the institutions of environmental development and other institutions (legal, political, social) that determine the overall management system of the sector.

\section{Conclusion}

The institutional environment of the extractive industries (IE EI) can be described with the O. Williamson's four-level typology of institutions. The IE EI includes formal institutions of the state and the contract system that establish the rules for the implementation of transactions in the field of subsoil use. The completeness and quality of the IE EI determine the effectiveness of the subsoil resources management system, and as a result, the effectiveness of the extractive industries and the level of its contribution to sustainable development. If the rates of economic growth are low, and the contribution of the extractives sector to the development of the country is insufficient, the institutional mechanisms responsible for this should be changed. The formation of an effective IE EI can launch the process of transition of a resource-dependent country to its sustainable development.

Extractive industries in RDE countries can be considered as elements of the global primary mineral resource sector. The 2030 Agenda for Sustainable Development has soft incentive impacts on the global extractives sector in three dimensions: economic, social and environmental. International sectoral initiatives broadcast relevant targets and conditions for their achievement at the national level, helping to identify ineffective institutional mechanisms and introduce more effective ones. The institutionalization of international sectoral initiatives and the introduction of best practices at the national and corporate level should be seen by countries with RDE as an opportunity and a way to increase the competitiveness of the national mining sector in order to meet the goals of sustainable development. 
The extractive industry leaves a significant carbon footprint and has a negative impact on the environment. The environmental dimension is present in 13 out of 17 SDGs, of which a significant relationship with the extraction of subsoil resources is observed in four SDGs $(12,13,14,15)$, where the share of the environmental dimension is more than $40 \%$. To the traditional environmental problems of the extractives sector added the threat of climate change and its consequences. The environmental factor plays an increasingly important role in the financial markets. A clear example of this is the adoption of the EU Taxonomy, which conceptualized the approach of "sustainable investment", limiting the access to the international financial capital for projects that do not meet environmental sustainability criteria. Environmental regulation should become an integral part of "good governance" in the extractive industries of countries with RDE, which will increase their investment attractiveness.

\section{Acknowledgements}

The article was prepared with the financial support of the Russian Foundation for Basic Research and the Ministry of Culture, Education, Science and Sports of Mongolia in the framework of the scientific project No. 19-510-44013\20.

\section{References}

1. A Roe, S. Dodd, Dependence on Extractive Industries in Lower-income Countries, In: Addison, T. and Roe, A (ed) Extractive Industries: The Management of Resources as a Driver of Sustainable Development (2018)

2. R. Torvik, European Economic Review, 45, 285 (2011)

3. C. Brunnschweiler, E. Bulte, Environmental Economics and Management, 55(3), 248 (2008)

4. H. Mehlum, K. Moene, R. Torvik, The World Economy, Wiley Blackwell, 29(8), 1117 (2016)

5. P. F. Kaznacheev, Resource Rents and Economic Growth. Economic and Institutional Development in Countries with a High Share of Income from the Sale of Natural Resources. Analysis and Recommendations Based on International Experience

6. Weishu Leong, Kamiar Mohaddes, Institutions and the Volatility Curse (2011)

7. D. North, Institutions, Institutional Change and Economic Performance (Cambridge University Press, 1990)

8. S. Voigt, Journal of Institutional Economics, 9(1), 1 (2013)

9. E.T. Ayuk, A.M. Pedro, P. Ekins, Mineral Resource Governance in the 21st Century Gearing Extractive Industries Towards Sustainable Development. Summary for Policymakers and Business leaders (2020)

10. E. Dietsche, Political Economy and Governance. In Extractive Industries: The Management of Resources as a Driver of Sustainable Development (2018)

11. O. E. Williamson, Journal of Economic Literature, 38(3), 595 (2000)

12. M. Bevir, Governance: A very short introduction (Oxford, UK: Oxford University Press, 2012)

13. Global governance: possibilities and risks, Baranovsky, V.G, Ivanova, N.I. (ed). IMEMO RAN (2015) 
14. UNDP and UN Environment, Managing mining for sustainable development: A sourcebook. Bangkok: United Nations Development Programme (2018)

15. T. Addison, Climate Change and the Extractives Sector. In: Extractive Industries: The Management of Resources as a Driver of Sustainable Development (2018)

16. O. Vidal, B. Goffé, N. Arndt, Nature Geoscience, 6, 894 (2013)

17. Regulation (EU) 2020/852 of the European Parliament and of the Council of 18 June 2020 on the establishment of a framework to facilitate sustainable investment, and amending Regulation (EU) 2019/2088. OJ L 198, 22.6.2020, 13

18. M. Wachenfeld, Research, Extracting Good Practices: A Guide for Governments and Partners to Integrate Environment and Human Rights into the Governance of the Mining Sector, UNDP (2018) https://extractiveshub.org/

19. International Resource Panel (IRP) of the United Nations Environment Programme 